\title{
Da tradição em Psicossomática às Considerações da Daseinsanálise
}

Cristine Monteiro Mattar
Universidade Federal Fluminense, RJ, Brasil.
Ana Luiza das Chagas Aleixo
Universidade Federal Fluminense, RJ, Brasil.
Nathalia Correa Aizman
Universidade Federal Fluminense, RJ, Brasil.

\author{
Ana Maria Lopez Calvo de Feijoo \\ Universidade do Estado do Rio de Janeiro, RJ, Brasil. \\ Carolina Labanca Marcondes Gomes \\ Universidade Federal Fluminense, RJ, Brasil. \\ Paula Zanuto Maués \\ Universidade Federal Fluminense, RJ, Brasil.
}

Tainá Cordeiro Gonçalves

Universidade Federal Fluminense, RJ, Brasil.

\begin{abstract}
Resumo: Este artigo busca refletir sobre a dualidade entre soma e psique, que tende a obscurecer a unidade originária a partir da qual esses dois entes podem aparecer e serem compreendidos. Em seguida, conduz o leitor para uma compreensão crítica, lidando com aspectos da tradição em psicossomática e com base na fenomenologia-hermenêutica de Martin Heidegger e na Daseinsanalyse de Medard Boss. Tanto o filósofo alemão quanto o psiquiatra suíço operam não somente a desconstrução da ótica tradicional, mas também do próprio conceito de psicossomática. Mostram que o modo de acesso ao fenômeno produz a dicotomia, sendo, portanto, necessário modificá-lo a fim de apreender o que está em jogo no problema do corpo e do adoecer, isto é, a própria existência do homem que se revela todo o tempo através do corporar (Leiben), que é sempre gesto. Este último significa, em Heidegger, toda expressão do homem, indissociável de seu existir no mundo como Dasein. Este estudo tem a expectativa de contribuir na busca de outros fundamentos para a prática do cuidado psicológico em saúde.
\end{abstract}

Palavras-chave: Psicossomática, Tradição, Daseinsanálise.

\section{From Psychosomatic tradition to considerations on Daseinsanalysis}

\begin{abstract}
The article presents aspects of the psychosomatic tradition and attempts to reflect on the duality generated between soma and psyche, which tends to overshadow the original unity from which these two entities can appear and be understood. Subsequently, it leads the reader to a critical comprehension based on Martin Heidegger's hermeneutic phenomenology and Medard Boss' dasensanalysis. Both the German philosopher and the Swiss psychiatrist dismantle not only the traditional view but also the concept of psychosomatics. They argue that the route of access to the phenomenon produces a dichotomy, which therefore proves itself necessary to be modified so that one can perceive what is at stake in terms of the body and of getting ill, i.e., the human existence which at all times reveals itself through bodying (Leiben), which is always gesture. The former means, in Heidegger, each human expression which is indistinguishable from their existence in the world as Dasein. Thus, this article contributes to the search of other fundamentals for the psychological practice in healthcare.
\end{abstract}

Keywords: Psychosomatics, Tradition, Daseinsanalysis.

O presente trabalho foi financiado pela FAPERJ. 


\title{
De la tradición en Psicosomática a las consideraciones del Daseinanalyse
}

\begin{abstract}
Resumen: El artículo presenta los aspectos de la tradición en psicosomática y reflexiona sobre la dualidad engendrada entre soma y psique, que tiende a ocultar la unidad originaria desde la que estos dos entes pueden aparecer y ser comprendidas. Luego, conduce al lector a una comprensión crítica basada en la fenomenología- hermenéutica de Martin Heidegger y el Daseinanalyse de Medard Boss. Tanto el filósofo alemán como el psiquiatra suizo hacen no solo la deconstrucción de la óptica tradicional, sino también del propio concepto de psicosomática. Ellos enseñan que el modo de acceso al fenómeno produce dicotomía y por lo tanto, es necesario modificarlo para captar lo que está en juego en el problema del cuerpo y del enfermar, es decir, la existencia misma del hombre se revela todo el tiempo por medio de la corporalidad (Leiben), que siempre es gesto. Gesto para Heidegger significa toda expresión del hombre, inseparable de su existencia en el mundo como Dasein. Se cree que con esto se está contribuyendo a la búsqueda de otros fundamentos para la práctica del cuidado psicológico en las instituciones que cuidan de la salud.

Palabras clave: Psicossomático, Tradición, Daseinsanálise.
\end{abstract}

\section{Introdução}

O termo 'psicossomática' surgiu no século passado, com o médico alemão Heinroth (1773-1843). Se, em 1818, Heinroth apresentava uma publicação intitulada Desordens da alma, dez anos depois, em 1828, começava a aparecer em seus escritos a denominação somatopsíquica. Assim, é possível distinguir duas definições que influenciam suas obras, bem como suas diferentes direções: a alma, no início, e a dicotomia soma e psíquico, posteriormente (Castro, Andrade, \& Müller, 2006; Mello Filho, 1992). Em um primeiro momento, esse Heinroth acreditava na influência das paixões sexuais no aparecimento de algumas doenças, como a tuberculose, a epilepsia, o câncer e a insônia, o que ele denominou como desordens da alma. Após dez anos, ele introduziu o termo somatopsíquica ao referir-se à influência de fatores orgânicos nos efeitos emocionais, com o poder de modificar o estado psíquico (Castro et al., 2006; Silva, \& Müller, 2007).

Essa forma de pensar algumas doenças do soma como expressão do psíquico, de maneira geral, encontra-se presente na atualidade sob a denominação de medicina psicossomática, que orienta o psiquiatra inserido no hospital geral na realização da interconsulta (Blumenfield, \& Tiamson-Kassab, 2010). O psiquiatra, com essa orientação, deverá estar atento aos sintomas psíquicos, vistos como efeitos previsíveis de diversos tipos de adoecimento, bem como aos problemas de origem psíquica que poderão resultar em disfunções orgânicas. Há uma lista extensa que classifica os principais problemas que podem resultar em solicitação de consulta psiquiátrica, a serem tratados por áreas que passam a ser denominadas psico-oncologia, psicocardiologia, psiconefrologia, trauma e queimadura, psicologia da paciente obstétrica etc. Tal classificação chama a atenção, pelo empenho em categorizar os chamados fenômenos psicossomáticos ou somatopsíquicos, apontando para a gênese do transtorno ora no corpo, ora na psique, bem como estabelecendo relações de causalidade entre as duas instâncias, que são tomadas como dicotômicas. A perturbação em uma delas pode gerar efeitos na outra, o que leva a uma prática que requer a atuação de dois profissionais, o médico a quem cabe o tratamento do somático e o psiquiatra e/ou psicólogo aos quais fica designado o psiquismo, ou seja, o tratamento dos efeitos psicológicos decorrentes da doença, como a depressão, a ansiedade, o medo dos tratamentos e o medo da morte (Blumenfield, \& Tiamson-Kassab, 2010). Assim, toda a compreensão das enfermidades passa a ser tomada em uma dualidade soma e psique. Isso acaba por criar um fosso entre a existência e a teoria, que muitas vezes, é motivo de descrença, seja por parte do médico, do profissional psi ou mesmo do leigo. O médico, quando imbuído dessa descrença, 
acaba por reduzir tudo ao somático, enquanto o profissional psireduz ao psíquico e o leigo, descrente, fica em uma ou outra interpretação.

A psicossomática, que aqui denominamos de tradicional, opera com referenciais que se inserem em uma realidade tomada como dicotômica e pela lei da causalidade, acabando por obscurecera unidademais originária, em que a existência não aparece por meio a disjunção. O mais originário desse aparecer, ou seja, a existência, é que cria a condição de possibilidade de surgimento do soma e psique dicotomizados. Como afirma Heidegger (2001), o soma e a psique aparecem tardiamente. O obscurecimento daquilo que aparece primariamente é a marca de nosso tempo, daí que a predominância do pensamento dicotômico sobre o fenômeno da psicossomática, modo de pensar que persiste mesmo quando se tenta escapar dessa polaridade.

Mello Filho (1992) define a psicossomática como ideologia e campo de pesquisas sobre a saúde, o adoecer e as práticas de saúde, isto é, ideias sobre a relação mente-corpo e os mecanismos de produção de enfermidades. Além disso, ela é uma prática relacionada à medicina integral e, recentemente, vem assumindo cada vez mais o seu papel integrador e multidisciplinar. O conceito de psicossomática evoluiu em três fases, sendo a inicial ou psicanalítica aquela que refletia o predomínio dos conceitos psicanalíticos - questões do inconsciente, das teorias da regressão e dos benefícios secundários do adoecimento, entre outros; a fase intermediária ou behaviorista, que se caracterizava pelo incentivo às pesquisas, cujos achados trouxeram contribuições aos estudos do estresse; e a fase atual, ou multidisciplinar, que traz à tona a importância do social e da psicossomática como atividade que exige interação entre diversos profissionais de saúde (Mello Filho, 1992).

No Brasil, a Psicossomática ganhou corpo através da atuação de psicanalistas em hospitais de ensino no Rio de Janeiro, em São Paulo, Porto Alegre e Recife. A circulação das ideias e práticas construídas, nestes trabalhos para outros profissionais da área da saúde, contribuiu na criação da Associação Brasileira de Medicina Psicossomática. Segundo Mello Filho (1992), atualmente, as atividades que recebem o nome de Psicossomática ou Psicologia Médica compreendem o ensino e prática de aspectos bem amplos, tais como:

[...] todo tipo de fenômenos de saúde e de interações entre pessoas, como as relações profissionais-pacientes, as relações humanas dentro de uma família ou de uma instituição de saúde, a questão das doenças agudas e crônicas, o papel das reações adaptativas ao adoecer, à invalidez, à morte, os recursos terapêuticos extraordinários (p. 20).

Conforme Abram Eksterman (1992), se considerarmos que a Medicina Psicossomática inclui em seu conceito os aspectos psicológicos do adoecer, a relação médico-paciente e seus múltiplos efeitos, e, por fim, a ação terapêutica em relação ao doente, entendido como um todo biopsicossocial, então, podemos considerar que o início do movimento psicossomático brasileiro se deu na década de 1950. Esse autor situa como marco psicossomático da medicina do Brasil a tese de livre-docência do médico Danilo Perestrello, A psiquiatria atual como psicobiologia, de 1945, a qual é permeada por ideias baseadas na perspectiva psicossomática. Tais ideias se expandiram para a prática médica treze anos depois, quando Perestrello fundou a Divisão de Medicina Psicossomática no Serviço de Clínica Médica do Hospital Geral da Santa Casa do Rio de Janeiro, em 1958 (Eksterman,1992).

Eksterman (1992) também considera que o movimento psicossomático se expandiu para outras profissões da área da saúde, que passaram a pensar nas questões psicológicas envolvidas no adoecer humano. No entanto, ele acredita que muito pouco se tem tocado nas duas questões fundamentais à Medicina Psicossomática, que são, a seu ver: 1) considerar que a doença no homem sempre inclui o viés simbólico segundo o qual ele é constituído, o que implica no conhecimento de suas características psicossociais; e 2) o sucesso terapêutico está intimamente ligado à relação médico-paciente. Por isso, torna-se fundamental que as práticas vinculadas à perspectiva psicossomática se comprometam com essas duas questões-chave.

A partir dessas referências, que obviamente não esgotam o tema em sua complexidade, é possível afirmar que a dicotomização mente-corpo e sua consequente relação, na interpretação da origem da saúde e da doença, têm sido a tônica quando o tema é psicossomática. Silva e Muller (2007) referem-se a Lipowsiki como um estudioso que problematiza o atual critério dicotômico de compreensão da psicossomática, propondo-se a pensar o homem em sua integralidade, isto é, em sua totalidade, 
num complexo mente-corpo em interação com um contexto social. Compartilhando do mesmo pensamento, Mello Filho (1992) definiu psicossomática como uma ideologia sobre o adoecer, a saúde e suas práticas, bem como um campo de pesquisas sobre esses fatos e como prática de uma medicina integral. No entanto, ainda que hoje o termo seja definido mais em relação à visão ideológica desse movimento, nas pesquisas sobre a relação mente-corpo e sobre os mecanismos de produção de enfermidades, em que se destacam os fenômenos do estresse, vê-se ainda a forte referência à dualidade soma e psique. Embora se refiram ao homem sob uma ótica integral, tais concepções, ainda, são bastante marcadas pela tradição em psicossomática, a qual, sem dúvida, deve seu desenvolvimento às teorias psicanalíticas sobre o adoecer. No presente texto, destacam-se as ideias de Freud, Groddeck e Winnicott.

\section{A psicossomática em Freud, Groddeck e Winnicott}

Pesquisar a psicossomática em Freud (1856-1939) nos remete a um entendimento de sua teoria sobre a sexualidade como sendo a principal responsável pelo desencadeamento da histeria, em que a divisão soma e psique surge em consequência de uma defesa psíquica. É assim que, no terceiro volume de sua obra, datada de 1893 a 1899, na conferência intitulada Sobre o mecanismo psíquico dos fenômenos histéricos, Freud (1893\1987a) nos presenteia com essa frase: "as razões imediatas do desenvolvimento dos sintomas histéricos devem ser buscadas na esfera da vida psíquica" (p. 37). Este excerto será o norteador de sua linha de pensamento, tornando clara sua crença em uma divisão $a$ priori entre a vida psíquica - onde se dá o recalcamento de situações reais-e a vida sintomática-onde aparecem os sintomas como forma de manter recalcada a experiência psíquica, através da simbolização no corpo.

O sintoma que aparece no corpo nem sempre é fácil de ser identificado, ou seja, não se sabe a partir de qual situação traumática foi adquirido, pois essa é uma relação simbólica e o símbolo-sintoma não revela diretamente sua origem psíquica. Segundo o próprio Freud (1893/1986): “É como se houvesse a intenção de expressar o estado mental através de um estado físico, e o uso linguístico fornece uma ponte pela qual isso pode ser efetuado" (p. 42-43).

Essa divisão das esferas psíquica e somática advém de uma vontade do próprio paciente quando, no momento do trauma, faz uma divisão de sua consciência entre o que pode e não pode ser lembrado. A isso Freud (1893/1986) chamou de "histeria de defesa" (p. 54). Tal divisão ocorre porque a situação traumática traz uma soma de excitação (afeto) muito grande, afeto esse que é transferido para algo somático. A essa transformação, Freud (1894/1986) chamou conversão, como se nota no texto As neuropsicoses de defesa, no qual afirma: "Na histeria a representação incompatível é tornada inócua pela transformação de sua soma de excitação em alguma coisa somática. Para isso gostaria de propor o nome de conversão" (p. 56). Nesse ponto de sua teoria, Freud dá um passo atrás e reconhece que entre o trauma psíquico - representação sexual - e a ligação de seu afeto com outra representação, é demandado do paciente um esforço mental que possui caráter inconsciente.

$\mathrm{Na}$ conferência intitulada Obsessões e fobias, datada de 1895, vê-se que o médico vienense aponta para uma nova forma de neurose, a "neurose de angústia" (p. 83). Esta, por sua vez, também é de origem sexual, porém, não possui mecanismo psíquico do recalque. Ela se dá no real, ou seja, pelo coito interrompido, devido à ejaculação precoce. Diz Freud (1895/1986a): "Sua causa específica é a acumulação de tensão sexual produzida pela abstinência ou pela excitação sexual não consumada" (p. 83).

$\mathrm{Na}$ conferência Sobre os fundamentos para destacar da neurastenia uma síndrome específica denominada neurose de angústia, Freud descreve uma vasta sintomatologia: irritabilidade geral, expectativa angustiada, hipocondria, angústia moral, ansiedade, espasmos, dificuldade de respirar, fome, suor, angústia rudimentar, ataques de angústia, sintomas isolados, sintomas unidos, pânico à noite e vertigem (Freud, 1895/1986b). Tanto a neurastenia quanto a neurose de angústia se caracterizam pelo mecanismo da conversão do afeto de uma representação forte em uma representação fraca. A diferença é que, na neurose de angústia, o sintoma não se origina de uma representação recalcada, mas sim da própria angústia causada pela transferência de afeto, da excitação sexual. O acúmulo de excitação é, segundo Freud (1895/1986b), de origem somática e de natureza sexual, sem participação psíquica. O que leva a crer que, para um bom entendimento do mecanismo da neurose de angústia, é preciso fazer uma "deflexão da excitação sexual somática da esfera psíquica” e do emprego anormal dessa excitação (p. 106). 
Para diferenciar-se, portanto, uma neurose de angústia de uma neurastenia (histeria), afirma Freud (1895/1986b):

[...] a diferença está apenas em que, na neurose de angústia a excitação, em cujo deslocamento a neurose se expressa, é puramente somática (excitação sexual somática), ao passo que, na histeria, ela é psíquica (provocada por um conflito) (p. 112).

Entretanto, ambas possuem a experiência sexual como condição primordial para o aparecimento dos sintomas histéricos. Essa conclusão é também expressa por Freud (1896/1986) na conferência A etiologia da histeria:

[...] qualquer que seja o caso e qualquer que seja o sintoma que tomemos como ponto de partida, no fim chegamos infalivelmente ao campo da experiência sexual. Aqui, portanto, pela primeira vez, parece que descobrimos uma precondição etiológica dos sintomas histéricos (p. 185).

Quando um sujeito histérico passa por uma situação traumática de grande excitação, o afeto perante a situação é desviado para alguma parte de seu corpo, que age como o substituto do afeto, por onde será descarregado o quantum de excitação que criará no sujeito uma reação física, podendo ser, muitas vezes, o choro ou a dor em alguma parte do corpo. Freud (1893\1987b) explica melhor esse fenômeno na conferência Considerações teóricas: "As experiências que liberaram o afeto original, cuja excitação foi então convertida num fenômeno somático, são por nós descritas como traumas psíquicos, e a manifestação patológica que surge desta forma, como sintomas histéricos de origem traumática” (p. 215).

Com a repetição da situação traumática, o sintoma se transforma em puramente somático, deixando a ideia que deu lugar a ele completamente recalcada, imperceptível. Portanto, ao analisarmos a teoria de Freud, é possível perceber claramente a distinção feita entre a psique como porta de entrada na histeria, e o soma como o lugar do aparecimento e representação dos sintomas, estando soma e psique relacionados, porém, não unificados.

Outro teórico importante sobre o tema da psicossomática de inspiração psicanalítica foi o médico alemão Georg Groddeck (1866-1934), que iniciou, em 1917, o período analítico de sua obra escrita ao publicar Determinação psíquica e tratamento psicanalítico das afecções orgânicas, considerada um marco da medicina psicossomática. Segundo Groddeck (1923/1984), a doença seria uma criação do paciente, não possuindo uma causa externa ao corpo. O homem utilizaria fatores do exterior para provocar suas enfermidades, desde uma casca de banana na qual escorrega e se fere até o contato com um vírus que o faz contrair uma doença. Para Groddeck, o sujeito teria a intenção de sofrer por obter prazer com o seu sofrimento, como uma forma de se autopunir para espantar o sentimento de culpa, que faria parte da natureza humana. Entretanto, para Groddeck, geralmente não se tem acesso a essas questões, uma vez que elas são inconscientes, ou seja, se processam na instância psíquica que ele denominou como Isso.

Como considerava que toda doença tinha um sentido, não sendo nunca fruto do acaso, Groddeck propôs que o mecanismo psicológico da conversão histérica poderia ser generalizado para outras doenças somáticas, como expressão simbólica de desejos inconscientes manifestos no corpo do doente. Sendo assim, o médico alemão entendia a doença como uma solução problemática para os conflitos que perpassam cada homem: a doença seria uma forma do Isso representar um conflito íntimo que não pode ser dito de maneira consciente. Quanto mais profundo fosse este conflito, mais grave seria a doença e, através dela, era possível inferir o que precisava ficar escondido no inconsciente. Portanto, ao quebrar o braço, por exemplo, o paciente, inconscientemente, teria o desejo de cometer um crime, matando alguém ou assaltando com aquele braço, e quebrá-lo seria uma forma de não realizar tais atos.

A instância do Isso não faria distinção entre o corpo e o psiquismo, pois ambos seriam formas pelas quais o Isso se revela. Para Groddeck, portanto, o fundamento de todas as ações seria o Isso, o qual deveria ser interrogado em todo adoecer, uma vez que através da fala e de uma observação do paciente, se conseguiria chegar ao âmago das questões que causaram a doença, levando a associações e interpretações que poderiam conduzir à cura. Pode-se constatar que esse estudioso mantém a dicotomia soma e psique e o Isso seria o espaço de síntese entre esses dois polos.

Winnicott (1896-1971), pediatra e psicanalista inglês, acreditava em uma separação entre o somático e o psíquico no princípio da vida humana. 
Essa dicotomia, ao longo da história do indivíduo, poderia vir ou não a desfazer-se e o que determinaria esse desfecho seria o cuidado que a criança receberia nos primeiros anos de vida. Um desenvolvimento considerado normal incluía uma tendência de integração entre o corpo e a psique, mas em um ambiente falho, que não fornecesse ao frágil ego do recém-nascido a proteção necessária, essa tendência não se realizaria.

Winnicott (2000) enfatizou a necessidade de dissociar os conceitos mente e psique, que se confundem. Conceitua a mente como o que define as faculdades intelectuais e como um recurso para um entendimento da realidade. Ela emerge a partir de falhas graduais no ambiente, inéditas para a criança, que precisa se desvencilhar de sua onipotência anterior, numa tentativa de começar a entender o que está acontecendo. A psique, anterior a esse processo, é uma elaboração imaginativa do funcionamento corporal pelo bebê. Um ambiente suficientemente bom permite que essas elaborações se integrem ao corpo. Entretanto, um ambiente ruim, de negligência, não ajuda nessa integração de psique e corpo, chamada de personalização. No último caso, as falhas aparecem abruptamente sem que o bebê esteja preparado para lidar com elas, e a única saída que encontra é refugiar-se na mente, como acontece com psicóticos que possuem uma capacidade intelectual exacerbada (Winnicott, 2000). Nesse caso, a personalização conclui-se, precariamente, como se a integração se desse de maneira frouxa, com uma inclinação para um rompimento (para a psicose) a qualquer momento, sendo a matriz para o surgimento da doença psicossomática. Essa enfermidade psicossomática revela-se como o negativo de um positivo, por ser ela a responsável em manter uma ligação entre psique e soma, ainda que a integração completa não aconteça (Winnicott, 1989, p. 88). Na visão winnicottiana, portanto, sempre que houver uma experiência de grande abalo emocional e a tendência à cisão emergir, o organismo lançará mão de uma doença psicossomática para assegurar a frágil vinculação existente (Winnicott, 1989).

Como se pode notar, a compreensão psicanalítica acerca do fenômeno psicossomático atribui os sintomas do adoecer a uma dinâmica psíquica que possui repercussões no corpo, isto é, há uma psicogênese, ainda que se levem em conta os fatores ambientais, especialmente na teoria winnicottiana.
Com as considerações referidas anteriormente, pode-se acompanhar como a formulação da psicossomática nos termos da tradição, seja na psicanálise ou na medicina, movimenta-se na tentativa de não abandonar nenhum dos polos, ora enfatizando o psíquico, ora o somático. Assim, cada uma dessas áreas de estudo, ao tender para um deles, marca a originalidade do problema no somático ou no psíquico. Ou a expressão psíquica advém de uma fissura orgânica, logo é o orgânico que deve ser tratado para que a expressão psíquica seja corrigida; ou, ao contrário, é o psíquico que deve ser reparado, seja na ordem do conflito ou no desamparo originário, exclusivo da infância. Ambas as interpretações abandonam total e radicalmente a condição existencial mesma, que está sempre presente e é comum a todos nós.

A partir desse panorama das discussões sobre psicossomática, buscaram-se interlocutores outros, tanto na Filosofia quanto entre aqueles que, tendo sido formados em Medicina e ao mesmo tempo em um referencial psicanalítico, procuraram aproximar-se do problema por outra via. Dessa forma, recorreu-se ao pensamento de Martin Heidegger (1889-1976) e do médico suíço Medard Boss (1903-1990). Este último coloca a seguinte questão: "não seria possível, que em seu estado atual, a Biologia, a Filosofia e a Psicologia sejam impotentes para fornecer o horizonte da compreensão necessária à doença humana; e isto porque estas ciências repousam sobre premissas irrefletidas e inadequadas?" (Boss, 1954, p. 6). Ao referir-se ao estado atual, Boss falava da década de 1950, período no qual estava se apropriando, cada vez mais, de um pensamento mais originário, o de seu amigo e inspirador Heidegger.

A partir desse horizonte prévio de compreensão, no qual está em jogo a visão dicotômica de soma e psique, bem como a relação de causalidade que sustenta uma explicação da doença, outras interpretações do fenômeno ficam totalmente obscurecidas. Na tentativa de desobscurecer outras interpretações possíveis para o fenômeno em questão, é que se irá pensar em caminhos que podem se anunciar na medida em que forem tematizados.

\section{A destruição da dicotomia soma e psique em Seminários de Zollikon}

As temáticas do corpo e da psicossomática foram abordadas por Heidegger nos Seminários de Zollikon (2001), colocando em questão as noções de saúde, 
corpo e doença tal como abarcadas em uma perspectiva científico-natural. Para tanto, ele lançou mão da fenomenologia, dando um passo atrás com relação às interpretações vigentes e acompanhou tais fenômenos por um viés-hermenêutico. O filósofo alemão lembra que é preciso se demorar naquilo que é tido como óbvio, e por isso, permanece não tematizado e pouco questionado em seu sentido originário. Sobre a questão do corpo, por exemplo, afirma Heidegger: "Trata-se de reconhecer em que consiste, primariamente, o problemático do problema do corpo" (Heidegger, 2001, p. 104). Para se deter sobre essa questão, ele vai partir de uma conferência do médico Hegglin, no Primeiro Congresso da Sociedade Psicossomática da Suíça. Afirma que não se trata de desconsiderar a proposta do médico, mas de tecer críticas no sentido de realçar as diferenças, deixar ver. Para que seja possível desdobrar o psicossomático como problema é necessária uma crítica verdadeira, fenomenológica, ou seja, que permita primeiramente diferenciar o psíquico e o somático, a partir de um mesmo, o ser do homem como homem. No tema da psicossomática há uma diferenciação que se refere a esse mesmo e uno.

As pesquisas científicas não tornam evidente o ser do ente em sua propriedade, o ente de que se trata em cada caso. Na psicossomática, como afirmamos acima, inspiradas por Heidegger, "trata-se do ser-homem do homem” (Heidegger, 2001, p. 104). Ao referir-se à conferência de Hegglin, Heidegger (2001) afirma que o conferencista quer resumir todas as influências mútuas de psique e soma sob o conceito de Psicossomática, ao invés de reivindicar esta expressão somente para as doenças emocionais. Haveria, assim, na sua visão, as doenças psicossomáticas - quando problemas emocionais afetam o corpo, e as doenças somatopsíquicas, quando problemas corporais afetam o psíquico. O conferencista recebia críticas, como clínico, por fazer essa separação entre psique e soma, por não considerar a psique relacionado a todo o organismo. Diz o médico que pretende excluir especulações filosóficas para ater-se ao princípio simples que defende para diferenciar soma e psique. Para Hegglin, a diferença entre esses dois elementos é que os fenômenos psíquicos não podem ser pesados nem medidos, só podem ser sentidos intuitivamente, enquanto o somático pode ser apreendido por números. Assim, exemplifica: o luto não pode ser medido, mas as lágrimas podem ser examinadas numericamente. Hegglin abandona, desse modo, a unidade ser-homem do homem, que sustenta a polaridade soma e psique.

Heidegger (2001) diz que Hegglin abandona o elemento mais originário, o uno, e inaugura um princípio simples para a diferenciação entre psique e soma. Na conferência de Hegglin, o princípio de diferenciação de soma e psique é a maneira da compreensão diferente de soma e psique em que os fenômenos psíquicos não podem ser pesados, medidos, são sentidos intuitivamente; tudo que é somático pode de alguma forma ser compreendido por números: "Os dois âmbitos temáticos, psique e soma, são, pois, definidos (por Hegglin) em seu conteúdo a partir do modo de acesso a eles. O modo de investigação do âmbito de ser, o acesso a este, é referente à sua cognoscibilidade." (Heidegger, 2001, p. 106). Ou seja, os fenômenos psique e soma são diferenciados na tradição em psicossomática pelo modo de acesso e conhecimento e não a partir de si mesmos. O método de acesso a ambos tornou-se mais valorizado do que os próprios fenômenos psíquicos e somáticos. $\mathrm{O}$ fato de serem ou não mensuráveis passou a ser o critério de sua diferenciação. Trata-se de uma supervalorização do método em detrimento ao fenômeno.

No entanto, afirma Heidegger, o princípio simples citado na conferência como sendo científico e objetivo é, no entanto, evidentemente filosófico. É preciso refletir se o próprio princípio é pensado devida e suficientemente, e se for, como ele élimitado em seu âmbito e aplicado de acordo com isso. Heidegger pergunta se, a partir do modo de acesso a um âmbito, seu conteúdo pode ser determinado em ser-o-quê-e-como. De que modo a maneira de acesso é determinada?

Hegglin diz que os fenômenos psíquicos só podem ser sentidos intuitivamente e não são mensuráveis. Heidegger questiona (2001, p.106): "Por que razão o modo de acesso ao psíquico é a intuição, enquanto para o somático é a mensuração?". A razão está no modo de ser da psique e do soma. O princípio simples do médico diz: os âmbitos temáticos de psique e soma são determinados pelo respectivo modo de acesso, e o modo de acesso é determinado pela coisa, pelo soma e pela psique. Heidegger diz que o médico está girando em círculo, mas que este não é vicioso ou errado. O círculo pertence à estrutura essencial do conhecimento humano. Um quadro não pode ser apreendido matematicamente. Se quisermos apreendê-lo como obra de arte, não calcularemos, mas o olharemos intuitivamente. $\mathrm{O}$ quadro seria por 
isso algo psíquico? Não, o quadro não é nada psíquico. Heidegger diz que o princípio simples apresentado para a diferenciação entre a psique e soma "não é tão simples” (Heidegger, 2001, p. 107). De acordo com isto, somos confrontados com a pergunta: o que acontece com a diferenciação entre psique e soma, como ela deve ser feita, que reflexão é necessária para que isto fique esclarecido? E conclui: "A questão do psicossomático é, em primeiro lugar, uma questão de método" (Heidegger, 2001, p. 107). O método científico-natural produz o somático como mensurável em oposição ao psíquico, constituindo-os a partir do a priori da mensuração, como se esta fosse natural e necessária. No entanto, já se trata de um olhar que produz a verdade dos fenômenos como sendo mensuráveis ou não mensuráveis.

Voltando à conferência, que fala ainda em fundamentos das conexões entre soma e psique, Heidegger indaga o que isso significa. Significaria algo para o qual se pode exigir uma prova científico-natural? Entretanto, uma prova científico-natural para esta conexão entre psique e soma nem é possível, pois, pela exigência científica, estes fundamentos deveriam ser somáticos, pois só o somático seria mensurável, e só o que é mensurável pode ser provado de modo científico-natural. A prova não poderia apoiar-se em apenas um dos dois âmbitos em questão, o somático.

Aquilo que corresponde à exigência de conhecimento válido do cientista natural deve ser provável e provado pela mensuração. $\mathrm{O}$ autor da conferência exige que a relação entre soma e psique seja mensurável. Exigência injustificada, pois não provém da relação dos fatos em questão, mas sim da exigência e do dogma científico-natural: só seria real o que fosse mensurável. "Mas então as conexões entre psique e soma seriam algo psíquico, algo somático ou nem um nem outro?" (Heidegger, 2001, p. 107). Heidegger propõe, então, outro método para tentar sair do que chama de "beco sem saída".

Volta-se, então, para o problema do corpo. Retoma Ser e Tempo (Heidegger, 1927/2013), no parágrafo 23, onde fala sobre a espacialidade do ser-no-mundo. Assim, diz que a compreensão do corpo como aquilo que termina na epiderme está totalmente equivocada. O corpo vai muito além de sua materialidade, por isso nele se incluem seus direcionamentos. Podemos estar próximos de algo, podemos ouvir um barulho distante que nos faz tremer não porque o objeto ou o ruído sejam extensões de nosso corpo, mas, sim, porque o corpo transcende a epiderme e participa do nosso ser sempre junto $a$. Daí tratar-se de uma problemática espacial. O Dasein do homem é espacial em si, porque ordena o espaço e porque há uma espacialização do Dasein em sua corporeidade. "O Dasein não é espacial por ser corporal, mas sim a corporeidade só é possível porque o Dasein é espacial no sentido de ordenar" (Heidegger, 2001, p. 108).

Heidegger tenta, em seguida, alcançar a proximidade do fenômeno do corpo, mas sem a expectativa de solucionar o que chamou de problema do corpo. Para ele, já é muito conseguir apenas ver o problema. Ele, ainda, insiste na dificuldade de diferenciar o psíquico do somático e afirma que as lágrimas não podem ser medidas, como queria Hegglin. No máximo, se mede um líquido e suas gotas, mas não lágrimas, que só podem ser vistas diretamente. As lágrimas não são algo somático nem algo psíquico. Em outro exemplo, alguém enrubesce de vergonha e embaraço. O enrubescer também não pode ser medido. Mede-se, no máximo, a vermelhidão, pelo fornecimento de sangue. O enrubescimento não é algo somático nem algo psíquico. Assim, os critérios de separação do soma e psique pelo critério da possibilidade de medição, defendidos por Hegglin e pela ciência para diferenciar o somático do psíquico, caem por terra.

Fenomenologicamente, o enrubescimento da face ao envergonhar-se pode ser diferenciado daquele pela febre, a vergonha ou a entrada em um abrigo quente. Os três tipos acontecem na face, embora sejam muito diferentes e sejam diretamente diferenciados por nós no ser-com-os-outros quotidiano. Vemos no rosto do próximo se ele está constrangido ou aquecido, ou seja, vemos o gesto, expressão do ser-no-mundo, e tal leitura só pode ser feita por sermos com os outros, logo, prescindindo de critérios objetivos. É ao fenômeno como fenômeno que Heidegger propõe que devemos alcançar. Ver no rosto do outro a tristeza é possível, devido ao ser-com cotidiano, mas medir a tristeza não é possível. Dizer ele está um pouco triste não significa uma quantidade pequena de tristeza. $\mathrm{O}$ um pouco significa um modo (qualidade) de afinação.

O corpo, que nos parece o mais próximo, é o mais distante no espaço. Quando se tem dor nas costas, diz-se que ela se estende pelas costas, mas trata-se aí de outra espécie de espacialidade, que não é a extensão de superfície de um corpo material. Heidegger estabelece a distinção entre o corpo (Leib) 
e o corpo material (Körper). Afirma que os médicos ali presentes, com formação em anatomia e fisiologia, estavam orientados para o exame do corpo material $\mathrm{e}$, portanto, tinham outra ideia das condições corporais, diferentemente do leigo. No entanto, para Heidegger, a experiência do leigo estaria mais próxima do fenômeno da dor como fenômeno corporal, o qual seria praticamente impossível descrever com a ajuda da nossa visão de espaço habitual (Heidegger, 2001). À técnica do exame do corpo material, Heidegger contrapõe a experiência do leigo do corpo vivido, como sendo muito mais próxima de sua dor.

Heidegger (2001) afirma, por fim, que tentou tornar visíveis certos fenômenos como o enrubescer, a dor, a tristeza, deixando estes fenômenos ficarem simplesmente da maneira como os vemos, sem qualquer tentativa de reconduzi-los a qualquer coisa. Deve-se evitar qualquer tipo de possibilidade de relacioná-los e considerar até que ponto estes fenômenos já estão suficiente e completamente determinados em seu próprio conteúdo e se apontam para outros fenômenos aos quais pertençam essencialmente. Sempre já estivemos junto daquilo que vem ao encontro, trata-se, então, de executar este envolver-se no modo de ser em que sempre já estamos. Não se trata de conceituá-lo, de um mero compreender de algo como algo, mas sim de estar envolvido especialmente com o que vem ao encontro, sendo esta a "relação fundamental do homem com o que o encontra" (Heidegger, 2001, p. 135). Tornar-se atento ao que diz respeito inevitavelmente ao homem, mas que não lhe é imediatamente acessível. Relacionarse com algo como algo já é falar, ainda que não conceitue o que se mostra. Por exemplo, somos abertos para o espaço, nos movemos, sabemos onde algo deve estar, mas não precisamos olhar para o espaço como espaço, não precisamos defini-lo. Admite-se, assim, o espaço como algo aberto sem considerá-lo tematicamente, sem ocupar-se dele.

Dizer é o mesmo mostrar, deixar ver. O corpo está envolvido no ouvir e no ver, mas não é o corpo que vê, eu vejo; não é o olho que vê, mas sim meu olho, sou eu que vejo através de meus olhos. $\mathrm{O}$ corpo nunca vê o relógio, mas, mesmo assim, ele está junto quando vê o relógio. O homem corpora, diferentemente do relógio, que é transportado, o homem se move. O gesto de chorar ou enrubescer caracteriza o movimento como o meu movimento corporal, mas não se reduz a este. Diferentemente do animal, cujo movimento corporal não constitui gesto, o ser humano tem algo a dizer. Seu movi- mento fala, mostra, deixa ver, torna evidente. Através do corpo que é junto a, o gesto, ou seja, nosso mostrar-se se evidencia. $\mathrm{O}$ adoecer, portanto, nunca pode ser visto como um movimento ora corporal, ora psíquico. É de nós que ele fala, como gesto que nos evidencia. $\mathrm{O}$ gesto é o dizer que se fundamenta na evidência de que algo é. O adoecer, como todo corporar do Dasein no mundo, é um gesto, uma expressão do ser-no-mundo determinado pelo corporar do corpo. Cada movimento do meu corpo não entra simplesmente em um espaço indiferente como um gesto, como um comportamento desse ou daquele modo. O comportamento já está sempre numa região determinada, que está aberta através da coisa com que está relacionado, quando, por exemplo, pego algo na mão. "O corporar co-pertence sempre ao ser-no-mundo. Ele co-determina sempre o ser-no-mundo, o ser-aberto, o ter de mundo." (Heidegger, 2001, p. 123). Sendo assim, o ser-no-mundo jamais pode prescindir do corporar. Através deste, vem ao encontro todo o contexto existencial daquele que adoece, mas também o modo como se estruturam o hospital e as práticas dos profissionais de saúde.

\section{Daseinsanalyse e psicossomática}

Medard Boss, em sua obra Introdução à Medicina Psicossomática, de 1954, aponta para outra possibilidade de pensar as relações soma e psique, colocando em questão as tentativas de explicação do adoecer por uma somatogênese ou por uma psicogênese, que classifica como duvidosas. Boss (1954) pensa o adoecer em uma perspectiva daseinsanalítica e, nesse sentido, defende que todo o adoecer é sempre psicossomático, pois atinge a abertura que é o Dasein, ser-aí, como um todo, e representa uma restrição à determinada possibilidade, a doença com suas limitações, em detrimento de outras. Algo que nos atinge física ou psiquicamente já nos afetou de maneira mais originária, tendo em vista a nossa existência como abertura antes de tudo. Em cada adoecer, sugere Boss (1954), deve-se perguntar qual é a relação com o mundo que se encontra perturbada, quais as possibilidades existenciais que um determinado adoecer impede que se realizem.

Boss (1954), em uma tentativa definitiva de promover a unidade indissociável soma e psique, chega a apontar para a necessidade de que se extinga até mesmo o termo psicossomática, o qual, em si mesmo, ainda mantém a dualidade que se quer solucionar. Por fim, na apresentação do seu livro sobre psicossomática, Boss explicita essa tentativa: 
Psicossomática, com efeito, não sublinha uma dualidade do ser humano, que nós desejamos, precisamente, abandonar? Nós conservamos, apesar de tudo, esta designação corrente, já que ainda está longe de uma terminologia verdadeiramente adequada à essência da doença humana. Pois uma tradição bi-milenar nos fez considerar o homem como sendo composto de corpo, alma e espírito; e nos mantém prisioneiros de uma terminologia incômoda e imperfeita. É por isto, também, que na presente obra nos prenderemos menos à terminologia do que a uma descrição fiel dos fenômenos. Somente esta tarefa já exige uma longa investida e um novo olhar (Boss, 1954, p. 4).

Sobre o corpo, com base nas reflexões de Heidegger (2001) a esse respeito, nos diz Boss (1954, p.31): “O corpo constitui uma condição necessária, mas em nenhum caso $a$ condição suficiente da existência humana". Nossos órgãos sensoriais como soma funcionam por meio aos olhos, aos ouvidos, a língua, a pele, porém eles não podem ver, escutar, sentir, provar ou tocar. Apenas pela e na corporeidade, o homem se relaciona com aquilo que lhe vem ao encontro.

Ainda, com base nas considerações de Heidegger sobre o corpo, o médico suíço, afirma que a presença humana não se limita ao espaço ocupado pelo corpo. A corporeidade é uma das esferas do ser do homem, nela se atualiza a existência humana, que engloba os fenômenos do corpo e da alma, do somático e do psíquico. Embora diferentes, ambos constituem aspectos de uma mesma estrutura originária que é a existência humana, o modo de ser do homem, isto é, o Dasein ou ser-aí. A partir dessa abertura é que se pode vir a falar em soma e psique, ou seja, a corporeidade humana como esfera da existência se atualiza de modo físico ou somático. $\mathrm{O}$ aspecto corporal é o modo físico de relações com o mundo, relações que definem o que o Da-sein é. A doença é uma estagnação de possibilidades vitais na corporeidade. Na existência estagnada e reduzida, somente a corporeidade aparecerá sob um aspecto patológico e anormal, como inchaço, inflação e desfiguração dessa corporeidade.

Com base na concepção da existência em sua totalidade, Boss (1954) vai alavancar as suas interpretações sobre a medicina psicossomática. Assim ele irá mostrar diferentes situações que apontam para o modo de corporar do Dasein, dentre elas a predisposição aos acidentes, hipertensão arterial ou idiopática, as afecções crônicas idiopáticas do aparelho digestivo e a asma bronquial. Sobre a predisposição aos acidentes, após constatar, por meio de pesquisas das seguradoras acerca das causas dos acidentes que não eram as máquinas, nem o acaso, mas sim a falha humana dos próprios acidentados, Boss (1954) conclui que essas vivem em estado de tensão contínua em relação ao meio ambiente.

Quanto aos que sofrem de hipertensão essencial ou idiopática, Boss (1954) observa que são pessoas que vivem e corporalizam a existência como uma pressão constante, em que os vasos se tornam espessos e calcificados, e em que a corrente sanguínea é submetida a uma pressão crescente até que um vaso invisível cede e os liberta do peso esmagador da vida. No caso das afecções crônicas idiopáticas do aparelho digestivo, estas ocorrem frequentemente em pessoas em que há uma hiperconcentração existencial e em que o propósito da vida consiste no alcance máximo de poder, através de um trabalho de extrema dedicação. No entanto, pela idealização de seu projeto, tais indivíduos acabam sempre frustrados. Por restringir suas possibilidades, desconhecendo as outras, não podem senão tentar, sem cessar, alcançar a conquista da felicidade pelo acúmulo de bens materiais, que lhes permitam desempenhar um papel. Obcecado pelo impossível, enredado em via única, o indivíduo se vê como que apostando uma corrida cada vez mais acelerada, numa caça à felicidade mal-entendida, mal orientada, ou buscando atingir uma meta excessivamente limitada.

O fenômeno da asma brônquica por si só, obriga a considerar as contrações asmáticas dos bronquíolos e dos brônquios - esse sufocamento organo-neurótico da respiração - como a realização corporal de uma existência que, num mundo pleno de excitações violentas, se reduz a um terror imutável.

Observa-se que a compreensão sobre todas essas formas do adoecer, na perspectiva daseinsanalítica de Boss, remete imediatamente à existência que foi afetada na sua relação com o mundo, em sua unidade indivisível, torna-se impossível distinguir o que é psíquico ou o que é somático. O que remete à importância de conhecer os fundamentos e perspectivas teóricas associado às práticas do cuidado psicológico em saúde.

\section{Considerações finais}

Dejours (1989), embora não se dedique à fenomenologia, reconhece que o rompimento com a dicotomia soma e psique e as relações de causalidade entre esses 
dois polos foi plenamente operada por Heidegger, que teve seu desdobramento efetuado por Boss. Diz, ainda, queBoss em Introductionà la mèdecine phychosomatique interpreta os sonhos mantendo-se fiel a uma fenomenologia do corpo, isto é, sem a definição do sonho como algo psíquico e independente da corporeidade.

A tentativa de pensar o problema soma e psique em bases não dicotômicas e sem estabelecer uma relação de causalidade entre essas duas instâncias, no âmbito das ciências $p s i$, não é uma primazia de Boss. Michel Henry (1922-2002) também o fez com base naquilo que, inspirado em Husserl, ele denominou de fenomenologia da vida. Henry (1996), buscando encontrar o lugar mais originário a partir do qual se estabelecem as dicotomias, refere-se ao que chamou de afeç̧ão da vida, ou seja, diz que os afetos têm papel originário na constituição do Sie na relação deste com o mundo. Esta afecção da vida é dada como afecção do corpo, o que

\section{Referências}

Blumenfield, M., \& Tiamson-Kassab, M. (2010). Medicina psicossomática. Porto Alegre, RS: Artmed.

Boss, M. (1954) Introduction a la medicine psychosomatique. Paris: Presses Universitaires de France.

Castro, M. G., Andrade, T. M. R., \& Müller, M. C. (2006). Conceito mente e corpo através da história. Psicologia em Estudo, 11(1), 39-43.

Dejours, C. (1989). Lesdissidencesducorp. Paris: Payot.

Eksterman, A. (1992). Medicina psicossomática no Brasil. In J. Mello Filho, Psicossomática hoje (pp. 28-34). Porto Alegre, RS: Artmed.

Freud, S. (1986). Sobre o mecanismo psíquico dos fenômenos histéricos: uma conferência. In S. Freud, Primeiras publicações psicanalíticas. Rio de Janeiro: Imago. (Trabalho original publicado em 1893).

Freud, S. (1986). As neuropsicoses de defesa. In S. Freud. Primeiras publicações psicanalíticas. Rio de Janeiro: Imago. (Trabalho original publicado em 1894).

Freud, S. (1986a). Obsessões e fobias: seu mecanismo psíquico e sua etiologia. In S. Freud. Primeiras publicações psicanalíticas. Rio de Janeiro: Imago. (Trabalho original publicado em 1895).

Freud, S. (1986b). Sobre os fundamentos para destacar da neurastenia uma síndrome específica denominada neurose de angústia. In S. Freud. Primeiras publicações psicanalíticas. Rio de Janeiro: Imago. (Trabalho original publicado em 1895). ele denominou de corpoapropriação, isto é, a vida vem numa carne, num corpo subjetivo.

Neste manuscrito, foi por meio ao trabalho desenvolvido por Boss, inspirado em Heidegger, que se apresentaram, primeiramente, as concepções mais conhecidas sobre o fenômeno da psicossomática, a fim de realçar, em seguida, suas diferenças frente ao referencial fenomenológico-hermenêutico de Heidegger e Boss. Apontou-se para o modo como a tradição em psicossomática mantém a separação entre soma e psique, enquanto que a visão heideggeriana, ao sugerir outro modo de acesso ao fenômeno corporal, o toma como gesto que só pode ser apreendido em uma totalidade conjuntural, nunca isoladamente. Assim como o enrubescer e o estar triste, o estar doente também é um gesto que revela o Da-sein em seu modo de ser inseparável do solo originário no qual se movimenta, que é o mundo.

Freud, S. (1986). A etiologia da histeria. In S. Freud. Primeiras publicações psicanalíticas. Rio de Janeiro: Imago. (Trabalho original publicado em 1896).

Freud, S. (1987a). Sobre o mecanismo psíquico dos fenômenos histéricos. In S. Freud. Estudos sobre a histeria. Rio de Janeiro: Imago. (Trabalho original publicado em 1893).

Freud, S. (1987b). Considerações teóricas. In S. Freud. Estudos sobre a histeria. Rio de Janeiro: Imago. (Trabalho original publicado em 1893).

Groddeck, G. (1984). O livro disso. São Paulo: Perspectiva. (Trabalho original publicado em 1923).

Heidegger, M. (2013) Ser e tempo. Petrópolis, RJ:Vozes. (Trabalho original publicado em 1927).

Heidegger, M. (2001). Seminários de Zollikon. Petrópolis, RJ: Vozes.

Henry, M. (1996). Le cadavereindiscret. Paris: Abin. Mello Filho, J. (1992). Introdução. In Mello Filho, J., Psicossomática hoje (pp. 19-27). Porto Alegre, RS: Artmed.

Silva, J. D. T., \& Müller, M. C. (2007). Uma integração teórica entre psicossomática, stress e doenças crônicas de pele. Estudos de psicologia, 24(2), 247-256. doi:10.1590/S0103-166X2007000200011

Winnicott, D. W. (1989). A enfermidade psicossomática em seus aspectos positivos e negativos. In D. W. Winnicott, Explorações psicanalíticas (pp. 82-91). Porto Alegre, RS: Artes Médicas. 
Winnicott, D. W. (2000). A mente e sua relação com o psique-soma. In D. W. Winnicott, Da pediatria à psicanálise: obras escolhidas (pp. 332-346). Rio de Janeiro, RJ: Imago.

\section{Cristine Monteiro Mattar}

Docente da Universidade Federal Fluminense, Niterói - RJ. Brasil.

E-mail: cristinemattar.cm@gmail.com

Ana Maria Lopez Calvo de Feijoo

Docente da Universidade do Estado do Rio de Janeiro, Rio de Janeiro - RJ. Brasil.

E-mail: ana.maria.feijoo@gmail.com

Ana Luiza das Chagas Aleixo

Acadêmica da Universidade Federal Fluminense, Niterói - RJ. Brasil.

E-mail: analu_aleixo@hotmail.com

\section{Carolina Labanca Marcondes Gomes}

Acadêmica da Universidade Federal Fluminense, Niterói - RJ. Brasil.

E-mail: labanca.carol@gmail.com

Nathalia Correa Aizman

Acadêmica da Universidade Federal Fluminense, Niterói - RJ. Brasil.

E-mail: nath_pig@hotmail.com

\section{Paula Zanuto Maués}

Acadêmica da Universidade Federal Fluminense, Niterói - RJ. Brasil.

E-mail: paulazanuto@hotmail.com

\section{Tainá Cordeiro Gonçalves}

Acadêmica da Universidade Federal Fluminense, Niterói - RJ. Brasil.

E-mail: taina_cg@hotmail.com

Endereço para envio de correspondência:

Universidade Federal Fluminense, Instituto de Ciências Humanas e Filosofia, Campus Gragoatá. CEP: 24210-350.

Niterói - RJ. Brasil.

Recebido: $15 / 07 / 2014$

Aprovado: 31/03/2016

Received: $07 / 15 / 2014$

Approved: 03/31//2016

Recibido: $15 / 07 / 2014$

Aceptado: 31/03/2016

Como citar: Mattar, C. M., Feijoo, A. M. L. C., Aleixo, A. L. C., Gomes, C. L. M., Aizman, N. C., Maués, P. Z., \& Gonçalves, T. C. (2016). Da tradição em psicossomática às considerações da daseinsanálise. Psicologia: Ciência e Profissão, 36(2): 317-328. doi:10.1590/1982-3703001032014

How to cite: Mattar, C. M., Feijoo, A. M. L. C., Aleixo, A. L. C., Gomes, C. L. M., Aizman, N. C., Maués, P. Z., \& Gonçalves, T. C. (2016). From psychosomatic tradition to considerations on daseinsanalysis. Psicologia: Ciência e Profissão, 36(2): 317-328. doi:10.1590/1982-3703001032014

Cómo citar: Mattar, C. M., Feijoo, A. M. L. C., Aleixo, A. L. C., Gomes, C. L. M., Aizman, N. C., Maués, P. Z., \& Gonçalves, T. C. (2016). De la tradición en psicosomática a las consideraciones del daseinanalyse. Psicologia: Ciência e Profissão, 36(2):317-328. doi:10.1590/1982-3703001032014 